\title{
Chapter 3 \\ Requirements for Documentation, Data Collection and Scientific Evaluations
}

\author{
Dominic Rihan, Sven S. Uhlmann, Clara Ulrich, Mike Breen, \\ and Tom Catchpole
}

\begin{abstract}
This chapter describes the process and evaluation behind several of the flexibility elements introduced into the Basic Regulation. Firstly, it describes how a fishery may be granted a "high survival exemption" (HSE) or "de minimis" to the Landing Obligation, for a particular regulated species. It details the process of generating any exemption supporting evidence by Member States and the evaluation process. The impact of the Landing Obligation on the scientific advice for setting fishing opportunities is also described as well as the annual reporting process. The final section deals with the challenges faced by the main players in this whole process.
\end{abstract}

Keywords De minimis $\cdot$ Delegated act $\cdot$ European Commission $\cdot$ Flexibility $\cdot$ High survival · ICES · Joint recommendations · Landing Obligation · STECF · TACs and quotas

Electronic Supplementary Material The online version of this chapter (https://doi.org/10.1007/ 978-3-030-03308-8_3) contains supplementary material, which is available to authorized users.

D. Rihan ( $ه)$

Bord Iascaigh Mhara, Dun Laoghaire, Co. Dublin, Ireland

e-mail: Dominic.Rihan@bim.ie

S. S. Uhlmann

Flanders Research Institute for Agriculture, Fisheries and Food, Oostende, Belgium

C. Ulrich

DTU Aqua, Technical University of Denmark, Kgs Lyngby, Denmark

M. Breen

Institute of Marine Research (IMR), Bergen, Norway

T. Catchpole

Centre for Environment, Fisheries \& Aquaculture Science (Cefas), Lowestoft, UK

(C) The Author(s) 2019

S. S. Uhlmann et al. (eds.), The European Landing Obligation,

https://doi.org/10.1007/978-3-030-03308-8_3 


\subsection{Introduction}

According to the Basic Regulation (EU) 1380/2013, the Common Fisheries Policy (CFP) recognises that to ensure good governance, decision-making should, among others, be based on the principles of best available scientific advice. Scientific advice comprises the provision of catch advice for setting fishing opportunities, and evaluation and assessment of specific elements of the CFP. This chapter describes the new challenges that the Landing Obligation (Article 15) has posed to the two main advisory bodies: ICES (the International Council for the exploration of the Sea) and STECF (the EU Scientific, Economic and Technical Committee for Fisheries).

The main role of ICES has been to change the focus of the advice provided to the EU Commission from landings to catches to take account of the new management approach under the Landing Obligation. In this context, ICES has considered how best to provide information corresponding to wanted (i.e. catches above minimum conservation reference sizes) and unwanted catches (i.e. catches below minimum conservation reference sizes) and also to estimate catches discarded under exemptions to the Landing Obligation. ICES has also developed advice and methodologies to support experimental work in relation to high survivability exemptions, building on initial work by STECF. Additionally, ICES has received specific requests from the Commission to consider the impacts on the removal of TACs (ICES 2017) and amending specific Regulations (e.g., the sprat box in the North Sea).

STECF performs scientific work directly requested by the EU Commission. The main body of work carried out by STECF with regard to the Landing Obligation has been in assessing the main provisions and flexibilities provided for in Article 15 and the likely impacts of applying such mechanisms. To date STECF has held nine Expert Working Groups to advise on various aspects of the Landing Obligation (STECF 2013, 2014a, b, c, d, 2015a, b, 2016a). STECF (2015c) has also developed a methodology for the calculation of increases in TACs to take account of catches previously discarded (i.e., so-called TAC uplifts). Finally, STECF has reviewed the mandatory annual reports provided by Member States and the Advisory Councils on the implementation of the Landing Obligation (STECF 2016a).

\subsection{High Survival Exemption}

Article 15, paragraph 2(b), of the CFP describes an exemption from the Landing Obligation for "species for which scientific evidence demonstrates high survival rates, taking into account the characteristics of the gear, of the fishing practices and of the ecosystem". Clear, defensible, scientific evidence is required to support any proposal for such an exemption for selected species or fisheries. The inclusion of this provision within the CFP has sparked a sudden and uniquely synchronized interest in discard survival assessments and mobilised Member States and fishing industry representative organisations to apply for research projects to generate supporting evidence. 
In the 1990s and early 2000s, the importance of quantifying, and mitigating sources of unaccounted fishing mortality (e.g., discards, escapees, ghost fishing, illegal and unreported fishing) in addition to landed catches was recognised at ICES advisory level. This led to the establishment of several expert groups on unaccounted fishing mortality which also considered the survivability of escaping fish and discards (e.g., ICES 1995, 1997, 2005). However, these groups ceased to exist beyond 2009 due to a lack of activity in this research area, with funding prioritised elsewhere. With the inclusion of High Survival Exemptions (HSE) in Article 15 , interest in researching discard survivability has grown considerably. This section describes the process on (a) how HSE evidence is generated, (b) how it is submitted, and (c) which fisheries (species/métier) have been subsequently granted a HSE to the Landing Obligation after review by the European Commission and evaluation by STECF.

\subsubsection{Description of the Evidence}

Following STECF (2013) advice, ICES established a workshop on Methods for Estimating Discard Survival (WKMEDS) in January 2014, to provide guidance on how to quantify discard survival robustly. WKMEDS published its first draft guidance in April 2014 (ICES 2014), ahead of the evaluation of the first Joint Recommendations (JR) submitted by the regional groups of Member States. WKMEDS recommended: (i) assessments should be representative of discarded catch and practices, ideally at a métier scale; (ii) methods should avoid biasing results through observation induced mortality, and wherever possible demonstrated with appropriate controls; and (iii) the monitoring period should be sufficiently long to observe any delayed mortality attributable to the catch-and-discarding process.

To quantify (sub-) lethal stress and discard survival, three methodologies were identified: captive observation; tagging/biotelemetry; and vitality/reflex assessments; (ICES 2014; Breen and Catchpole in press). In captive observation, sub-samples of animals are selected from the discarded catch and monitored to provide estimates of survival rates. Tagging/biotelemetry use tagging technologies to monitor post-release mortality of (tagged) organisms. Vitality assessments quantify the health of the organism at the point of discarding. By combining vitality assessments with one or both of the other two techniques, the at-capture condition may be correlated with an individual's likelihood of post-release survival (Davis 2010). Depending on the strength of such a correlation, a vitality index may be used as a proxy for survival (e.g., Barkley and Cadrin 2012; Morfin et al. 2017).

Over a series of five subsequent meetings, WKMEDS provided an open forum for researchers and stakeholders actively involved in survival assessments to discuss and develop their methods (ICES 2015a, b, 2016a, b, c). Results from this group were disseminated to other interested ICES expert groups and were used by scientists to guide research efforts in this field (e.g., Uhlmann et al. 2016; Methling et al. 2017). 
The WKMEDS group also developed protocols for systematically reviewing survival assessments and meta-analysing survival data. Key questions were established (ICES 2015a, b; Catchpole et al. in submission) which should be considered by researchers and which may be used by external reviewers (i.e., STECF) to gauge the quality and robustness of any collected evidence.

\subsubsection{Evidence Collected So Far}

Spanning from the Mediterranean to the Baltic, more than 20 studies have been commissioned, in most cases with public funding, in at least 11 Member States, and Turkey between 2013 and 2018. An overview of the studied species, their survival rates and corresponding references has been included in an online supplement (Table 3.3; in Electronic supplementary material). A critical review of the survival rates of flatfish and Nephrops is in preparation (Catchpole et al. unpubl. data).

At least 20 species have been assessed for vitality status at the point of discarding and monitored for delayed mortality through captivity experiments. Species of such interest included flatfish such as Common sole (Solea solea), European plaice (Pleuronectes platessa), turbot (Scophthalmus maximus); pelagic species such as sardines (Sardina pilchardus), Atlantic salmon (Salmo salar), European seabass (Dicentrarchus labrax) and crustaceans such as Norway lobster (Nephrops norvegicus) and common spiny lobsters (Palinurus elephas). The prioritisation of species and fisheries to investigate was influenced by the potential for high survival, based on existing knowledge, and the likely timing for introduction under the Landing Obligation during the phasing-in period. The emphasis for research has recently turned to commercial skates and ray species, such as thornback ray (Raja clavata). This is, because it has been recognised that, despite indications that the HSE was originally intended for such relatively robust elasmobranch species in the first place (see Borges and Penas Lado, this volume), there are gaps in the evidence to support this.

Species discarded from both active and passive gear types have been studied including beam and otter trawls, Danish and purse seines, trammel-nets, gill nets, pots, creels and fish traps and some recreational hook-and-line fisheries.

It is fair to say that generating robust evidence on discard survival estimates that is representative of a fishery is challenging. Most studies have faced logistical difficulties in planning field trips and accommodating equipment onboard commercial or recreational charter vessels. Organisms monitored in captivity need to be housed in conditions sympathetic to their biological needs and should be monitored long enough for any fishing-related mortality to occur (Uhlmann et al. 2016; van der Reijden et al. 2017). Similarly, tagged organisms need to be monitored/detected/ recaptured in sufficient numbers to produce meaningful survival estimates based on detection/recapture rates. Some of these limitations mean that the generated evidence is not purely empirical, but also model-based. For example, extension models were developed to estimate survival in cases where monitoring periods could not be extended (Catchpole et al. 2015) or where it was not possible to house fish holding facilities on-board (Morfin et al. 2017). 


\subsubsection{Review of the Evidence}

The evidence submitted by Member States to support requests for a HSE has been evaluated by STECF (STECF 2013, 2014a). These evaluations considered whether the survival assessment methods are appropriate, and whether the limitations of the results have been fully explored. The ICES (2014) guidance on survival assessment protocols has been used to promote best practice and harmonisation of recently conducted assessments (ICES 2014; 2015a). Furthermore, the guidance has provided a reference for critical review which is used by STECF to apply a systematic and consistent evaluation process. Assessing the robustness of evidence, and its representativeness across entire fisheries, has proved challenging for STECF, and many studies have been criticized for lacking sufficient data to adequately describe the potential variability in survival at the fishery scale (STECF 2014b, 2015a, 2016b). STECF has repeatedly emphasized, "that before considering the implementation of a high survival exemption, it should be remembered that avoidance of unwanted catch, through improved selectivity or other means, is the primary objective of the Landing Obligation" (STECF 2016b).

Defining what "high survival" means has also been challenging. STECF has highlighted that this is a subjective term that involves trade-offs between different management and societal objectives, driven by the management priority for that fishery at that particular time (e.g., improving stock sustainability; improving financial viability; or avoiding waste). However, survivability should be considered in the context of the discard rates in the fishery. If only a relatively small proportion of discarded fish are likely to survive then granting such an exemption would seem counter intuitive (STECF 2016b). This could be interpreted by some as opening a loophole in the legislation that could be used to circumvent the Landing Obligation (Stockhausen, this volume). But rigorous stock assessments accounting for discard survival are needed to evaluate what the consequences may be for a stock.

Using the evaluation by STECF on the discard survival evidence provided by the Member States, the EU Commission decides whether to grant exemptions. To date, eight of the three-year Discard Plans, contained in the 13 Commission Delegated Regulations enacted, have included survival exemptions, which have been approved by the EU Commission. These apply to five regions (Baltic Sea, Black Sea, North Western Waters, South Western Waters and the North Sea) and provide survival exemptions for a total of 11 species such as anchovy (Engraulis encrasicolus), herring (Clupea harengus), mackerel (Scomber scombrus), horse mackerel (Trachurus trachurus), jack mackerel (Trachurus picturatus), Atlantic cod (Gadus morhua), Atlantic salmon (Salmo salar), Norway lobster (Nephrops norvegicus), common sole (Solea solea), turbot (Scophthalmus maximus), and scallop (Pecten jacobeus) caught in specific areas and fishing gears. The empirical estimates of discard survival derived from experimentation for these species caught in specific fisheries and areas range from 46-90\% survival. Several high survivability exemptions are also in place for highly migratory species, such as tunas and billfish. These exemptions implement recommendations emanating from relevant Regional Fisheries Management Organisations (RFMOs), such as ICCAT (STECF 2017a). 


\subsection{De Minimis}

Article 15, paragraph 2(c) of the CFP allows for de minimis exemptions of up to 5\% of total annual catches of all species subject to the Landing Obligation that can be discarded. Such catches are not counted against quotas, but must be recorded in fisher's logbooks, such as Electronic Reporting Systems (ERS). According to Recitals $29 \& 31$ of the CFP, the application of de minimis should be considered as a "last resort" mechanism and only after other technical or tactical approaches to avoid capture of unwanted catch have been fully explored. De minimis exemptions in the CFP are subject to two conditions, "where scientific evidence indicates that increases in selectivity are very difficult to achieve" or "to avoid disproportionate costs of handling unwanted catches, for those fishing gears where unwanted catches per fishing gear do not represent more than a certain percentage, to be established in a plan, of total annual catch of that gear".

The first of the STECF meetings in 2013 took this provision to mean that the spirit and general purpose of the de minimis provision ('a small discard proportion'), was to provide a 'safety valve' allowing for some discarding in the most difficult circumstances (STECF 2013). Accordingly, STECF outlined the types of information that would be needed to justify such exemptions, based on the conditions contained in the Regulation. While the de minimis exemption allows for minimal levels of discarding to be authorised, it does not provide a solution to quota restrictions that could result in the cessation of fishing (a so called 'choke' event). The de minimis provision does not enable more catches to be taken, but rather provides flexibility on how catches are handled onboard and the destination of those catches.

\subsubsection{Description of the Evidence}

At an early stage, STECF identified that the concept of de minimis exemptions was largely an economic argument (STECF 2013, 2014a, d). It was based on the logic that at a certain level of improvement in selectivity, losses of marketable catches would render the fishery in question uneconomic or that handling of unwanted catches on board would significantly increase the costs to the vessel owner, similarly threatening the viability of the business. On this basis STECF advised that, Member States should provide evidence to support these arguments (STECF 2013, 2014a).

For the first condition, in respect of improvements in selectivity, STECF (2013) put forward an approach using a 'break-even indicator' as a tool for evaluating potential de minimis cases. This was designed to show that the larger the change in selectivity towards unwanted fish, the more significant the decrease in revenue could be, due to losses of marketable catches. This was described as the ratio of current revenue to break even revenue (CR/BER) and shows how close the current revenue of a vessel or fleet is to the revenue required for it to break even. If the ratio is negative, variable costs exceed current revenue, indicating that the more revenue is generated, the greater the losses. 
For the other condition, STECF interpreted that, based on the wording in the Regulation, there was no need to identify and justify what disproportionate costs would be. However, providing studies that demonstrate the scale of additional costs of handling and sorting unwanted catches on board, coupled with the increased labour costs associated with these operations on board, would be useful. The wording in the article suggests that disproportionate costs of handling unwanted catch are assumed when the unwanted catch of a specific fishing gear is below a certain percentage of the total catch of that gear, and that the percentage threshold would be established in a discard plan. The key question to STECF appeared to relate to 'the percentage unwanted'. On this basis STECF did not explore this issue any further at that stage.

In 2016, STECF re-visited the de minimis issue and provided further guidance in the form of an analytical framework to assist in the submission of economic cases for de minimis exemptions. The framework proposed was based on an option appraisal methodology, applying a multi-criteria performance matrix to structure the analysis and present the results (STECF 2016b). The objective was to create a methodological framework to improve consistency in the economic analysis provided in support of de minimis submissions.

\subsubsection{Evidence Collected So Far}

Despite the provision of these detailed guidelines, in reality, unlike the proposals on the basis of high survivability, requests for de minimis exemptions submitted by the regional groups have varied considerably in terms of the quality and type of the evidence supplied. It is evident from the Joint Recommendations submitted, Member States have struggled to put together compelling cases to support de minimis exemptions, while STECF has found it difficult to evaluate the proposals, particularly those justified under the disproportionate costs conditionality. The CR/BER approach and multi-criteria performance matrix have not been used by Member States and instead the approach taken has been ad hoc and based on rather generic and simplistic arguments.

To justify requests under the first condition, Member States have focused on the results from one or more selectivity studies. The results of such studies generally show losses of marketable catch associated with the use of selective gears. Using simple analyses of the economic impacts of such losses on the whole fleet, Member States have attempted to demonstrate that improvements in selectivity are difficult to achieve. An example of this is in the beam trawl fishery for sole in the North Sea, where there is considerable evidence to suggest that increasing selectivity by increasing mesh size will result in high losses of sole with only marginal gains in terms of reduction in unwanted catches (STECF 2015a; Bayse and Polet 2015).

This argument has been used in most cases for de minimis exemptions. However, there are examples where Member States have attempted to demonstrate the impacts of handling and storing unwanted catches to justify these as "disproportionate costs". 
Examples include the French "EODE" study (Balazuc et al. 2016) and a Dutch impact assessment carried out by Buisman et al. 2013. In several other cases the argument for the de minimis exemption is on the basis that the costs for handling and disposing of unwanted catches ashore are disproportionate given there are limited outlets for such catches. Such a justification has been used in the cases of de minimis exemptions in the Mediterranean and in this case has been based on information supplied by the Mediterranean Advisory Council (STECF 2014b, 2017b).

\subsubsection{Review of the Evidence}

STECF has continued to struggle to review the evidence provided to support de minimis exemptions, although over time improvements in the quality of cases put forward by Member States have been noted by STECF (STECF 2016b, 2017b). Increasingly, particularly in the North Sea and North Western Waters, the case for an exemption has been conditional on vessels using a selective gear, the justification being that it is difficult for selectivity to be improved any further and the de minimis covers the residual unwanted catches. For instance, an exemption in the beam-trawl fisheries for sole in the North Sea and NWW (North Western Waters) is linked to the use of an escape panel to reduce unwanted catches of sole and plaice (STECF 2015a). Such cases seem much more in the spirit of the Regulation than cases where the de minimis seems to be requested to support a status quo of discarding practices in specific fisheries.

It has now been more or less accepted that the original break-even indicator approach and option appraisal framework are too complex; requiring data that are not available in many cases. In response, STECF has refined its advice and developed a simple template for the regional groups to provide an overview of the fleets involved and the catch data used to calculate the de minimis volume (STECF 2016b). STECF has then evaluated whether the supporting information supplied sufficiently demonstrates significant economic losses in the absence of a de minimis exemption. Regional groups have tended to follow this approach and the evaluation process has become more consistent; accepting that in many cases there is still a lack of relevant supporting information that demonstrates economic losses rendering fisheries potentially uneconomic. In these cases, STECF have tended to give "neutral" advice which neither endorses nor rejects out of hand any exemption. In all cases, the ultimate decision to grant an exemption lies with the Commission.

To date, all the discard plans have contained de minimis exemptions, which have been approved by the Commission, following the STECF evaluation. In total 42 exemptions are in place. These apply across a wide range of fisheries and apply to single stocks. Table 3.1 summarizes the extent of de minimis across the different sea basins and shows the progression since implementation of the Landing Obligation began in 2014. Once a de minimis provision is awarded, it is deducted from the TAC before the remainder is allocated to the relevant Member States, based on the understanding that this amount will be caught and discarded. So far, the de minimis 


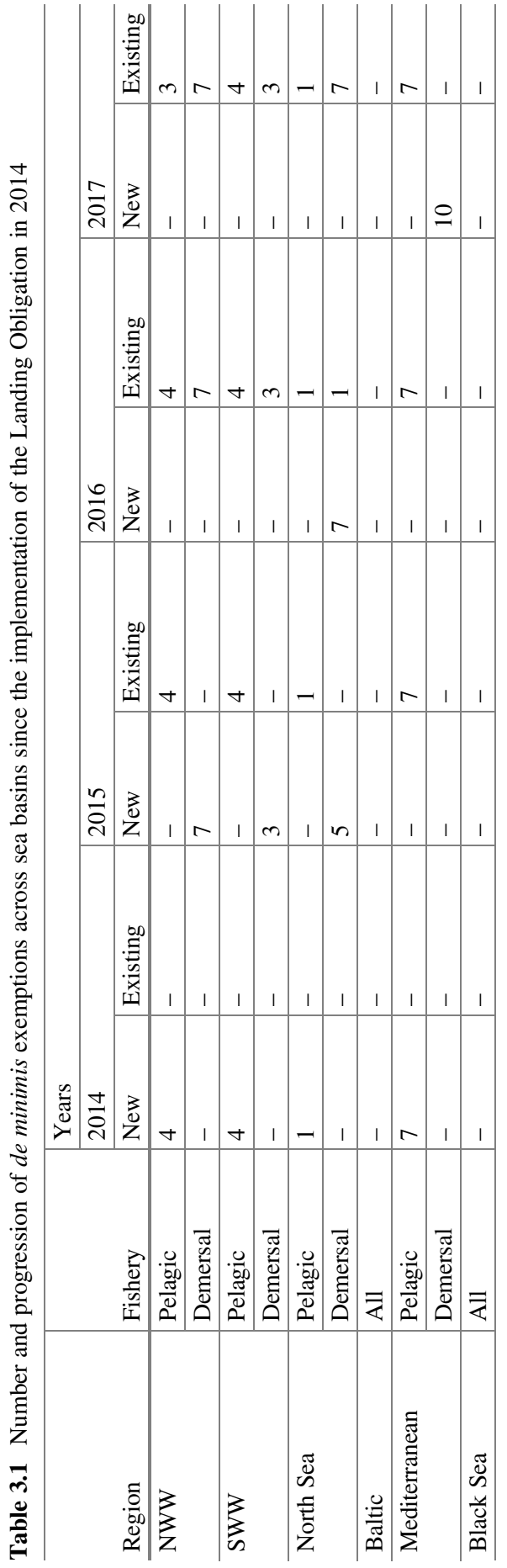


exemptions have been based on single stock, however, Member States have also requested evaluations on using de minimis for combinations of stocks. The regulation refers to the 'total annual catches of all species subject to an obligation to land to which de minimis can apply' and therefore does not preclude a de minimis being applied to a combination of stocks. STECF has noted that, while a combined de minimis may provide some flexibility where some unwanted species may be more difficult to handle than others, they may result in higher deductions from the TACs than for the single stock approach, and therefore reduced fishing opportunities (STECF 2018).

\subsection{Impact of the Landing Obligation on the Scientific Advice on Fishing Opportunities}

\subsubsection{ICES Advice}

Scientific advice for fishing opportunities for North East Atlantic stocks is provided by ICES. The advice involves two processes. First, stock assessments estimate the current status of the stock and its historical development. Second, short-term forecasts estimate the catches in the following year corresponding to a given management target. The target is usually expressed in terms of a fishing mortality which reflects a broad management objective (management plans, MSY or Precautionary Approach). Stock assessments for the main commercial stocks are based on catch-atage estimates. Initially, catches comprised only landings, but discard estimates by fishing activity ("metier") have been increasingly available through improved sampling programs financed by the EU Data Collection Framework (Council Regulation (EC) No 199/2008). There is also a requirement for vessel operators to record discard amounts for commercial species, however, limited compliance has meant that the log book data provide a gross underestimate of discard levels and reliance on these data is inadvisable (STECF 2013). Because of the limited coverage of scientific discard sampling, estimates are not available for all stocks and métiers in all Member States. Informed procedures have thus been developed over time to raise estimates of discard ratios and allocate age structure to the unsampled strata, usually through a dedicated ICES Database called InterCatch. ${ }^{1}$ In 2015, the scientific advice therefore included a complete provision for both landings and discards by métiers for most commercial stocks.

The Landing Obligation poses a significant conceptual and technical challenge, and has rendered the provision of scientific advice more complex to perform and quality-check, and more difficult to formulate. Since 2015, two main changes have been triggered in the ICES process, involving the way catch data are collected and the way forecasts are performed and presented.

\footnotetext{
${ }^{1}$ http://ices.dk/marine-data/data-portals/Pages/InterCatch.aspx
} 
Changes in catch data have emerged from the need to quantify and raise new categories. It is still considered that even if landed, a part of the catch is still not targeted by fishermen, but they cannot be called discards anymore and are referred to as "unwanted catch", while landings are now referred to as "wanted catch". To keep track of these categories, the InterCatch database was expanded in November 2015, and now includes five categories:

- $\mathbf{L}=$ Landings. Landings above minimum size;

- $\mathbf{B}=$ BMS Landings. Landings below minimum conservation reference size, BMS. Relevant for stocks under the landing obligation. The BMS landing will consist of BMS landings and predator damaged fish.

- $\mathbf{D}=$ Discards. The part of the catch which is thrown overboard into the sea and not registered in the logbook. This is still based on fishery observer estimates and applying to all stocks, both under and outside the Landing Obligation.

- $\mathbf{R}=$ Logbook Registered Discard. Relevant for stocks under the Landing Obligation. Logbook registered discard are discards, which are registered in the logbook and are under the exemption rules (e.g. de minimis). Damaged fish can be included under this Logbook registered discard.

- $\mathbf{C}=$ Catch can be used for a few species, for which there is no separation in the information of landings or discards

The sum of $(\mathrm{B}+\mathrm{D}+\mathrm{R})$ is the "unwanted catch" and corresponds to what was previously recorded as $\mathrm{D}$ alone. Thus, there are now many more strata to fill and raise in the stock assessment process. Even until now, the R and B categories have remained negligible, and conceptual decisions must be made on how to sample, monitor and include these catch components in the stock assessment. The categories B and R are usually not sampled directly, but being considered "unwanted", they are allocated an age distribution from the category $\mathrm{D}$.

Additionally, the logbook systems in place prior to the Landing Obligation were not able to deal with the new categories, and software updates have been required in all Member States. Depending on when and how updates took place, and on whether $\mathrm{B}$ and $\mathrm{R}$ information are transmitted to the scientific institutes, differences in reporting of all these categories to ICES have been observed across Member States.

The second major change in the process relates to the advice itself; i.e. to the maximum tonnage advised by ICES to be in line with the management objective. The target fishing mortality (e.g., $\mathrm{F}_{\mathrm{msy}}$ ) corresponds to the quantity of dead fish to be removed from the population, regardless of whether they are landed or discarded. Previously, the advice was expressed in terms of landings, assuming a given share of discards based on previous years' observations. In theory, the Landing Obligation would ensure that all catches would be landed, and a single catch advice would suffice. In practice, this poses a number of quantitative challenges, linked to the facts that: (i) discarding still takes place and cannot be ignored; and (ii) legal provisions (e.g., high survivability, de minimis and predator damage fish) in article 15 mean that the Landing Obligation is only partially applicable, particularly during the transition period 2015-2018 where not all fleets catching the same stocks have been phased-in 
at the same time, leading to partial uplifts (see below). It has been impossible to formulate single catch advice that would encompass this management complexity. ICES has therefore chosen to issue advice as a single maximum catch value split between wanted and unwanted shares, leaving it to the Commission to decide the actual level of the TAC. Combined together, the scientific information has become more complex to collect, to use and to quality-check, and to explain to clients in a simple and transparent manner.

\subsubsection{TAC Uplifts}

An added complexity in setting fishing opportunities is the inclusion of a provision within the CFP that allows for TAC adjustments to be made for those stocks under the Landing Obligation. This takes account of fish that otherwise would have been discarded but are now to be landed. These adjustments are to be made based on the contribution by the fleets under the Landing Obligation to total catches and discards of the concerned stocks. This is contained in Article 16(2) of the CFP and, at the time of the CFP negotiations, this was a key condition for Member States in agreeing to the Landing Obligation.

This would seem a relatively straightforward exercise under full implementation of the Landing Obligation, as the start point for the TAC would be the full catch advice provided by ICES less any deduction for fish discarded under exemptions. However, the methodology used for calculating TAC adjustments when setting the fishing opportunities has been the subject of extensive discussion; particularly in cases where available discard data is incomplete, or Member States chose to use catch thresholds based on historic landings to determine whether a vessel was subject or not to the Landing Obligation. This has been the case in the NWW, SWW and the North Sea where, in agreement with the Commission, Member States chose a phased implementation approach with partial coverage of certain stocks (e.g. In the NWW - "Where total landings per vessel of all species in 2013 and 2014 consist of more than $10 \%$ of the following gadoids: cod, haddock, whiting and saithe combined, the landing obligation shall apply to haddock"). This is illustrated in Table 3.2.

STECF provided advice to the Commission on how to calculate TAC adjustments and have developed a methodology to facilitate these calculations (STECF 2015c, 2017c):

- The ICES forecasts of catch and discards should be used as a starting point for calculating TAC adjustments consistent with FMSY principles. Fleet specific discard rates derived from the STECF database should then be used to determine fleet specific TAC adjustments.

- For stocks where the entire fishery or clearly defined fleet segments, are subject to the landing obligation, and for which specific discard rates are available, then calculation of TAC adjustments can simply be based on the ICES catch forecast. 


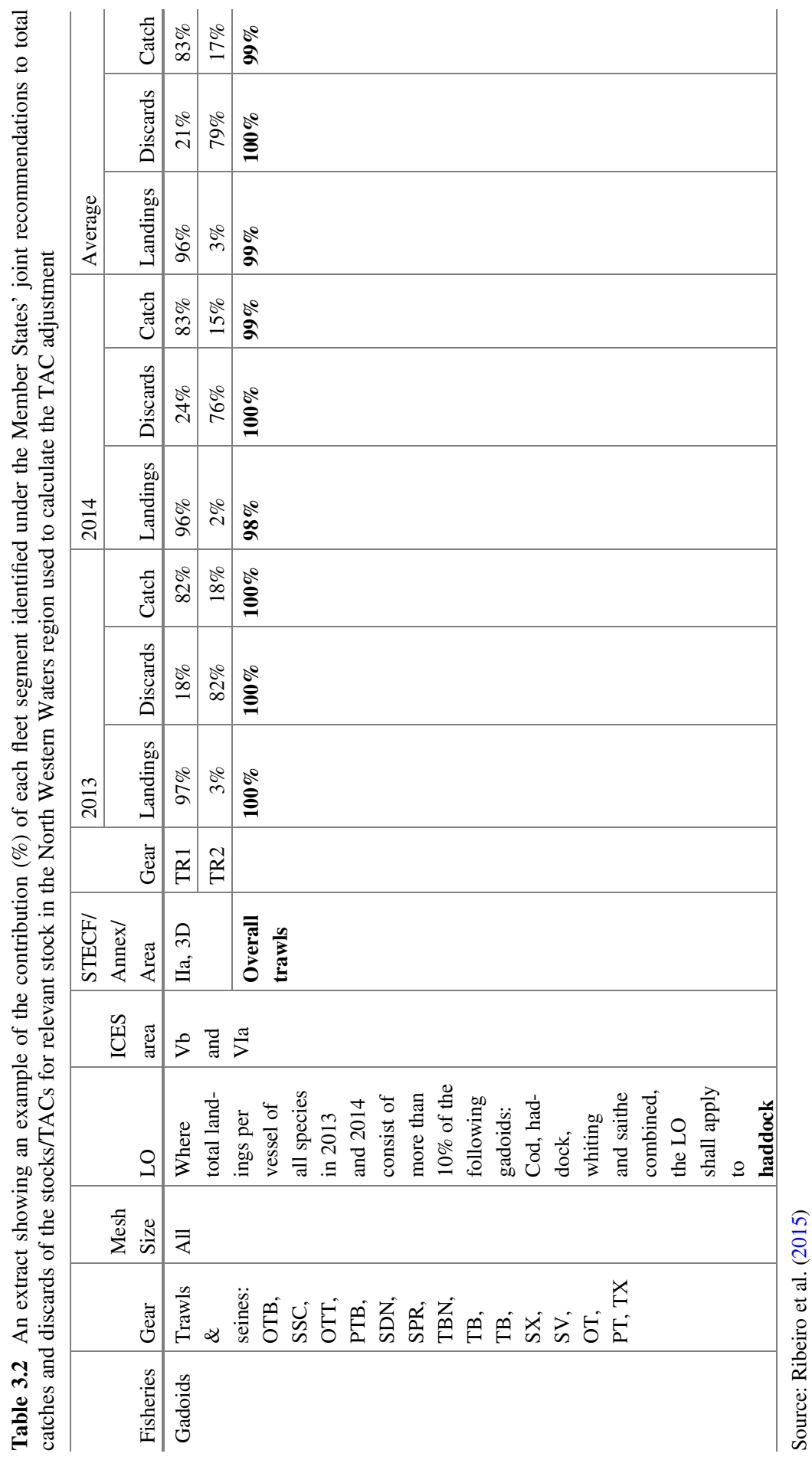


- In situations where only a proportion of vessels (within a specific fleet segment) and that also meet a historic landing composition threshold are subject to the Landing Obligation, then the average ICES discard rate should be applied to reflect the proportion of vessels and landings covered under the landing obligation.

This methodology has largely been followed up to and including the fishing opportunities set for 2018. The exception has been in the Baltic Sea, where the Landing Obligation has been fully implemented since 2016, with all stocks managed under TACs and the relevant fisheries being subject to the Landing Obligation. In these cases, the ICES catch advice has been applied. From 2019 onwards, in the other sea basins TAC adjustments will no longer be relevant and, as in the Baltic, the catch advice will be applied.

\subsection{Annual Reporting}

The CFP did not include a reporting requirement on the Landing Obligation. However, during the negotiation of the so-called "Omnibus Regulation" (Regulation (EU) No 2015/812), which aimed to remove incompatibilities of existing technical and control measures with the Landing Obligation by amending or repealing such measures, a mandatory reporting requirement was introduced. It covers seven elements and is based on information from, among others, the Member States and the Advisory Councils concerned. The elements are as follows:

- steps taken by Member States and producer organisations to comply with the landing obligation;

- steps taken by Member States regarding control of compliance with the landing obligation;

- information on the socioeconomic impact of the landing obligation;

- information on the effect of the landing obligation on safety on board fishing vessels;

- information on the use and outlets of catches below the minimum conservation reference size of a species subject to the landing obligation;

- information on port infrastructures and of vessels' fitting with regard to the landing obligation; for each fishery concerned; and

- information on the difficulties encountered in the implementation of the landing obligation and recommendations to address them.

After submission of the first reports in 2016, covering implementation in 2015, the Commission requested STECF review the reports submitted and also to provide guidance on the structure of future reports to improve their utility (STECF 2016a). STECF was also requested to identify additional elements that could be usefully reported on.

Following the assessment of the 2015 submissions from Member States and Advisory Councils, STECF concluded that, while they provided some insights into 
the operation of the Landing Obligation, they were generally lacking in structure and quantitative information (e.g., catch documentation, levels of funding, number of vessels impacted) making it difficult to undertake any substantive evaluation. For this reason, STECF developed a questionnaire to allow for ease of reporting in a structured way. At the same time STECF discussed other metrics that might improve the monitoring of the Landing Obligation given that the reporting requirements contained in Article 15(14) focus on certain aspects of the Landing Obligation and its potential impacts mostly ashore at port level. STECF identified that there was a lack of emphasis relating to the monitoring of effects and impacts of the Landing Obligation in terms of what happens at sea and in the environment. In particular, impacts on catch and catch profiles, compliance, selectivity, spatial and temporal changes in fishing operations, longer term socio-economic and environmental effects are not covered.

Subsequently, STECF has carried out reviews of the annual reports in 2017 (based on information from 2016; STECF 2017a) and in 2018 (reporting on 2017; STECF 2018). In 2017, 21 Member States and three Advisory Councils submitted reports for 2016, while in 2018 STECF received reports from 15 Member States and two Advisory Councils, despite the reporting being a mandatory requirement. The information supplied has remained qualitative rather than quantitative, but as most Member States have followed the questionnaire, the information has at least been supplied in a semi-structured way.

Based on the most recent assessment by STECF it is interesting to note that implementation measures reported by Member States in response to the questionnaire do not necessarily imply successful implementation of the Landing Obligation or that it is achieving its aims. STECF base this on the fact that there is little or no evidence that there has been significant relevant change in fishing practices or adequate monitoring and control of fishing operations to implement the Landing Obligation (STECF 2018). This supports claims by Member States and the fishing industry that the transitional phase of implementation has been challenging. Many of the concerns are anticipated for the future and not yet necessarily observed and STECF concluded that the reports of limited impact in some regions such as the Mediterranean and Black Seas may also be related to non-implementation, rather than because the Landing Obligation does not pose any issue.

It remains to be seen whether the quality of the information supplied will improve and allow for a meaningful assessment of implementation of the Landing Obligation and its associated impacts. However, at the present time it provides the best opportunity for monitoring progress in the short to medium term.

\subsection{Conclusion}

It is well documented that the Landing Obligation is challenging for Member States to implement and for the fishing industry to comply with, but it has also created several challenges for science. STECF has found it difficult to provide conclusive 
advice on some aspects of the flexibilities and exemptions in the legislative text. The subjective nature of the conditions - "high survival", "very difficult to achieve" or "disproportionate costs" - and limited information in many cases means that there is a large element of expert judgement required rather than empirically assessing the quality of the science. In saying this, the quality of submissions to support the exemptions has improved since the first JR's were submitted in 2014. In particular, progress has been made in the execution of survival experiments, which in most cases closely follow the recommendations made by STECF and also ICES (T. Catchpole, unpubl., data).

STECF has also highlighted the limitations in the information presented, in the methodologies used or where there are inconsistences in the information provided. On many occasions, information is presented that shows, for example, increasing selectivity results in losses of marketable fish. But whether this constitutes a technical difficulty or whether these losses result in a reduction in revenue significant enough to render the fishery uneconomic are not questions that can be readily answered without further data and more detailed analysis. STECF has consistently acknowledged that providing detailed information for individual fisheries is challenging. It therefore has only been able to consider the validity of the supporting information underpinning proposed exemptions. The lack of economic data in many cases makes it impossible to do any meaningful analysis of the economic impacts.

With regard to exemptions based on high survivability, the wide range of factors that can affect survival lead to considerable variability in the survival estimates observed. However, identifying and quantifying these is difficult due to the relatively limited species-specific information and differences between assessment protocols. Judging the representativeness of individual or limited studies as an indicator of discard survival across an entire fishery is therefore difficult, given the range of factors that can influence survival and how they may vary in time even within a fishery. The choice of acceptable survival thresholds, in the context of article 15.2 (b), will depend on which objective in the CFP (e.g., avoidance of waste; improve stock sustainability; improve financial viability) is set as a priority.

Finally, the introduction of the Landing Obligation has increased the potential for uncertainty in the science supporting fisheries management in the EU. An increased emphasis on the use of selective technical measures to reduce unwanted catches (O'Neill et al., this volume; Reid et al., this volume) is likely to increase uncertainty in our understanding of harvesting/exploitation patterns (e.g., Breen and Cook 2002; Breen et al. 2016). That is, it cannot be assumed that all of the escaping/released animals will survive (e.g., Breen et al. 2007; Ingolfsson et al. 2007). Therefore, the actual reduction in fishing mortality, in real terms, will only be a proportion of what is perceived from the reduction in discards caught. Moreover, the magnitude and pattern of the escape/release related mortality is far more challenging to quantify and monitor than discard related mortality. Furthermore, both ICES and STECF have consistently highlighted the lack of reporting by vessel operators of fish discarded under exemptions, discards of fish currently not subject to the Landing Obligation and catches of fish below MCRS, which compromises the quality of stock assessments and the accuracy of catch forecast. The quality of science supporting the 
implementation of the Landing Obligation would strongly benefit from provisions that strengthen data collection in this respect (e.g. through innovative monitoring measures such as Remote Electronic Monitoring, see Chap. 18). STECF concluded that if the data situation does not improve and the true quantities being caught as reported do not reflect the actual removals, then this will have a significant impact on the quality of scientific advice and, without a precautionary approach in setting fishing opportunities, a key objective of the CFP in achieving MSY may be compromised.

Acknowledgments We are grateful to the contributions by and discussions with members of the ICES expert working group on methods for estimating discard survival (WGMEDS).

\section{References}

Balazuc, A., Goffier, E., Soulet, E., Rochet, M.J., Leleu K. (2016). EODE - Expérimentation de l'Obligation de Debarquement à bord de chalutiers de fond artisans de Manche Est et mer du Nord, et essais de valorisation des captures non désirées sous quotas communautaires, $136+$ 53 pp. Version Février 2016. https://www.comitedespeches-hautsdefrance.fr/wp-content/ uploads/2016/03/Rapport-final-EODE-Exp\%C3\%A9rimentation-de-1Obligation-de-

DEbarquement-CRPMEM-NPdCP-Version-f\%C3\%A9vrier-2016.pdf. Accessed 18 June 2018.

Barkley, A.S., \& Cadrin, S.X. (2012). Discard mortality estimation of yellowtail flounder using reflex action mortality predictors. Transactions of the American Fisheries Society, 141, 638-644. https://doi.org/10.1080/00028487.2012.683477.

Bayse, S., \& Polet, H. (2015). Evaluation of a large mesh extension in a Belgian beam trawl to reduce the capture of sole (Solea solea). ILVO Instituut voor landbouwen visserijonderzoek report, February 2015. 8 pp. https:/www.vissersbond.nl/wp-content/uploads/2015/11/Evalua tion-of-a-Large-Mesh-Extension-in-a-Belgian-Beam-Trawl.pdf. Accessed 3 July 2018.

Borges, L., \& Penas Lado, E. (this volume). Discards in the common fisheries policy: The evolution of the policy. In S.S. Uhlmann, C. Ulrich, S.J. Kennelly (Eds.), The European Landing Obligation - Reducing discards in complex, multi-species and multi-jurisdictional fisheries. Cham: Springer.

Breen, M. \& Cook, R. (2002). Inclusion of discard and escape mortality estimates in stock assessment models and its likely impact on fisheries management (ICES CM 2002/V: 27, p. 15).

Breen, M., Huse, I., Ingolfsson, O.A., Madsen, N., Soldal, A.V. (2007). SURVIVAL: An assessment of mortality in fish escaping from trawl codends and its use in fisheries management. EU Contract Q5RS-2002-01603. Final Report.

Breen, M., Graham, N., Pol, M., He, P., Reid, D., Suuronen, P. (2016). Selective fishing and balanced harvesting. Fisheries Research, 184, 2-8. https://doi.org/10.1016/j.fishres.2016.03. 014.

Buisman, E., Van Oostenbrugge, H., Beukers, R. (2013). Economische effecten van een aanlandplicht voor de Nederlandse visserij. LEI-rapport 2013-062. ISBN/EAN: 978-90-8615657-3. 48 pp. https://library.wur.nl/WebQuery/wurpubs/fulltext/283011. Accessed 3 July 2018.

Catchpole, T., Randall, P., Forster, R., Smith, S., Ribeiro Santos, A., Armstrong, F., et al. (2015). Estimating the discard survival rates of selected commercial fish species (plaice - Pleuronectes platessa) in four English fisheries (MF1234). Cefas report (p.108). 
Catchpole, T., Breen, M., Depestele, J., Kopp, D., Méhault, S., Madsen, N., et al. (submitted) A critical review of European discard survival assessments. Fish and Fisheries.

Davis, M.W. (2010, March). Fish stress and mortality can be predicted using reflex impairment. Fish and Fisheries 11:1-11. https://doi.org/10.1111/j.1467-2979.2009.00331.x.

ICES. (1995, April). Report from the study group on unaccounted mortality in fisheries (ICES CM 1995/B:1). Aberdeen, Scotland, UK.

ICES. (1997). Report from the Study Group on Unaccounted Mortality in Fisheries (ICES CM 1997). Hamburg Germany, April 1997.

ICES. (2005). Joint report of the study group on unaccounted fishing mortality (SGUFM) and the workshop on unaccounted fishing mortality (WKUFM) (ICES CM 2005/B:08. 68 pp). 25-27 September 2005, Aberdeen, UK.

ICES. (2014). Report of the workshop on methods for estimating discard survival (WKMEDS) (ICES CM 2014/ACOM:51, p. 114). 17-21 February 2014, ICES HQ, Copenhagen, Denmark.

ICES. (2015a). Report of the workshop on methods for estimating discard survival 2 (WKMEDS 2) (ICES CM 2014\ACOM:66, p. 35). 24-28 November 2014, ICES HQ.

ICES. (2015b, April 20-24). Report of the workshop on methods for estimating discard survival 3 (WKMEDS 3) (ICES CM 2015\ACOM:39, p. 47). London, UK.

ICES. (2016a). Report of the workshop on methods for estimating discard survival 4 (WKMEDS 4) (ICES CM 2015\ACOM:39, p. 57). 30 November-4 December 2015, Ghent, Belgium.

ICES. (2016b, May 23-27). Report of the workshop on methods for estimating discard survival 5 (WKMEDS 5) (ICES CM 2016\ACOM: 56, p. 51). Lorient, France.

ICES. (2016c, December 12-16). Report of the workshop on methods for estimating discard survival 6 (WKMEDS 6) (ICES CM 2016/ACOM:56, p. 49). Copenhagen, Denmark.

Ingolfsson, O.A., Soldal, A.V., Huse, I., Breen, M. (2007). Escape mortality of cod, saithe, and haddock in a Barents Sea trawl fishery. ICES Journal of Marine Science, 64(9), 1836-1844. https://doi.org/10.1093/icesjms/fsm150.

Methling, C., Skov, P.V., Madsen, N. (2017). Reflex impairment, physiological stress, and discard mortality of European plaice Pleuronectes platessa in an otter trawl fishery. ICES Journal of Marine Science, 74(6), 1660-1667. doi: https://doi.org/10.1093/icesjms/fsx004.

Morfin, M., Kopp, D., Benoît, H.P., Méhault, S., Randall, P., Foster, R., et al. (2017). Survival of European plaice discarded from coastal otter trawl fisheries in the English Channel. Journal of Environmental Management, 204(1), 404-412. https://doi.org/10.1016/j.jenvman.2017.08.046.

O’Neill, F. G., Feekings, J., Fryer, R.J., Fauconnet, L., Afonso, P. (this volume). Discard avoidance by improving fishing gear selectivity: Helping the industry help themselves. In S.S. Uhlmann, C. Ulrich, S.J. Kennelly (Eds.), The European Landing Obligation - Reducing discards in complex, multi-species and multi-jurisdictional fisheries. Cham: Springer.

Reid, D.G., Calderwood, J., Afonso, P., Fauconnet, L., Pawlowski, L., Plet-Hansen, K.S., et al. (this volume). The best way to reduce discards is never to catch them in the first place! In S.S. Uhlmann, C. Ulrich, S.J. Kennelly (Eds.), The European Landing Obligation Reducing discards in complex, multi-species and multi-jurisdictional fisheries. Cham: Springer.

Ribeiro Santos, A., Dolder, P., Reeves, S., Catchpole, T. (2015). Information to support decisions on TAC adjustments for stocks subject to the landing obligation in 2016. Request for services Ad hoc contract on TAC adjustments, 5th November 2014, (p. 41). https://www.researchgate. net/publication/306001036_SCIENTIFIC_TECHNICAL_AND_ECONOMIC_COMMIT TEE_FOR_FISHERIES_-_TAC_adjustments_for_stocks_subject_to_the_landing_obligation_ STECF-15-17. Accessed 13 July 2018.

Scientific, Technical and Economic Committee for Fisheries (STECF) - Landing obligation in EU fisheries (STECF-13-23). (2013). Publications Office of the European Union, Luxembourg, EUR 26330 EN, JRC 86112, (p. 115). 
Scientific, Technical and Economic Committee for Fisheries (STECF) - Landing Obligation in EU Fisheries - part II (STECF-14-01). (2014a). Publications Office of the European Union, Luxembourg, EUR 26551 EN, JRC 88869, (p. 67).

Scientific, Technical and Economic Committee for Fisheries (STECF) - 46th Plenary Meeting Report (PLEN-14-02). (2014b). Publications Office of the European Union, Luxembourg, EUR 26810 EN, JRC 91540, (p. 117).

Scientific, Technical and Economic Committee for Fisheries (STECF) - Landing Obligations in EU Fisheries - part 3 (STECF-14-06). (2014c). Publications Office of the European Union, Luxembourg, EUR 26610 EN, JRC 89785, (p. 56).

Scientific, Technical and Economic Committee for Fisheries (STECF) - Landing Obligations in EU Fisheries - part 4 (STECF-14-19). (2014d). Publications Office of the European Union, Luxembourg, EUR 26943 EN, JRC 93045, (p. 96).

Scientific, Technical and Economic Committee for Fisheries (STECF) - Landing Obligation - Part 5 (demersal species for NWW, SWW and North Sea) (STECF-15-10). (2015a). Publications Office of the European Union, Luxembourg, EUR 27407 EN, JRC 96949, (p. 62).

Scientific, Technical and Economic Committee for Fisheries (STECF) - Landing Obligation - Part 6 (Fisheries targeting demersal species in the Mediterranean Sea) (STECF-15-19). (2015b). Publications Office of the European Union, Luxembourg, EUR 27600 EN, JRC 98678, (p. 268).

Scientific, Technical and Economic Committee for Fisheries (STECF) - TAC adjustments for stocks subject to the landing obligation (STECF-15-17). (2015c). Publications Office of the European Union, Luxembourg, EUR 27547 EN, JRC 98384, (p. 16).

Scientific, Technical and Economic Committee for Fisheries (STECF) - Methodology and data requirements for reporting on the Landing Obligation (STECF-16-13). (2016a). Publications Office of the European Union, Luxembourg, EUR 27758 EN, https://doi.org/10.2788/984496.

Scientific, Technical and Economic Committee for Fisheries (STECF) - Evaluation of the landing obligation joint recommendations (STECF-16-10). (2016b). Publications Office of the European Union, Luxembourg; EUR 27758 EN; https://doi.org/10.2788/59074.

Scientific, Technical and Economic Committee for Fisheries (STECF) - 54th Plenary Meeting Report (PLEN-17-01). (2017a). Publications Office of the European Union, Luxembourg; EUR $28569 \mathrm{EN}$; https://doi.org/10.2760/33472.

Scientific, Technical and Economic Committee for Fisheries (STECF) - Evaluation of the landing obligation joint recommendations (STECF-17-08). (2017b). Publications Office of the European Union, Luxembourg, 2017, ISBN 978-92-79-67480-8, https://doi.org/10.2760/ 149272, JRC107574.

Scientific, Technical and Economic Committee for Fisheries (STECF) - Data and information requested by the Commission to support the preparation of proposals for fishing opportunities in 2018 (STECF-17-13). (2017c). Publications Office of the European Union, Luxembourg, 2017, ISBN 978-92-79-67485-3, https://doi.org/10.2760/628725, JRC108053.

Scientific, Technical and Economic Committee for Fisheries (STECF) - 57th Plenary Meeting Report (PLEN-18-01). (2018). Publications Office of the European Union, Luxembourg, ISBN 978-92-79-85804-8. https://doi.org/10.2760/088784. JRC111800.

Stockhausen, B. (this volume). How the implementation of the Landing Obligation was weakened. In S.S. Uhlmann, C. Ulrich, S.J. Kennelly (Eds.), The European Landing Obligation - Reducing discards in complex, multi-species and multi-jurisdictional fisheries. Cham: Springer.

Uhlmann, S. S., Theunynck, R., Ampe, B., Desender, M., Soetaert, M., Depestele, J. (2016). Injury, reflex impairment, and survival of beam-trawled flatfish. ICES Journal of Marine Science, 73 (4), 1244-1254. https://doi.org/10.1093/icesjms/fsv252. 
van der Reijden, K.J., Molenaar, P., Chen, C., Uhlmann, S. S., Goudswaard, P. C., van Marlen, B. (2017). Survival of undersized plaice (Pleuronectes platessa), sole (Solea solea), and dab (Limanda limanda) in North Sea pulse-trawl fisheries. ICES Journal of Marine Science, 74, 1672-1680. https://doi.org/10.1093/icesjms/fsx019.

Open Access This chapter is licensed under the terms of the Creative Commons Attribution 4.0 International License (http://creativecommons.org/licenses/by/4.0/), which permits use, sharing, adaptation, distribution and reproduction in any medium or format, as long as you give appropriate credit to the original author(s) and the source, provide a link to the Creative Commons license and indicate if changes were made.

The images or other third party material in this chapter are included in the chapter's Creative Commons license, unless indicated otherwise in a credit line to the material. If material is not included in the chapter's Creative Commons license and your intended use is not permitted by statutory regulation or exceeds the permitted use, you will need to obtain permission directly from the copyright holder. 